\title{
The Impact of Treatment on Quality of Life in Patients with Head and Neck Cancer
}

\author{
*Marta DACBROWSKA-BENDER ${ }^{1,2}$, Robert SEONIEWSKI ${ }^{3}$, Urszula RELIGIONI ${ }^{4}$, \\ Anna SLONIEWSKA ${ }^{5}$, Magdalena MILEWSKA ${ }^{1}$, Anna KUPIECKA ${ }^{2}$, Adrianna \\ SOBOL ${ }^{2,6}$, Anna STANISZEWSKA ${ }^{7}$
}

\author{
1. Dept. of Clinical Dietetics, Medical University of Warsaw, $W$ arsaw, Poland \\ 2. "Fundation Onko Cafe-Together Better", Warsaw, Poland \\ 3. Dept. of Public Health, Medical University of Warsaw, Warsaw, Poland \\ 4. Collegium of Business Administration, Warsaw School of Economics, Warsaw, Poland \\ 5. Masovian Oncological Hospital, Wieliszew, Poland \\ 6. Dept. of Oncological Prevention, Medical University of Warsaw, Warsaw, Poland \\ 7. Dept. of Experimental and Clinical Pharmacology, Medical University of Warsaw, Warsaw, Poland \\ *Corresponding Author: Email: marta.dabrowska@wum.edu.pl
}

(Received 07 Feb 2018; accepted 15 Feb 2018)

\section{Dear Editor-in-Chief}

Every year in the world there are 600,000 new cases of patients diagnosed with head and neck cancer $(1,2)$. In Poland head and neck cancer accounts for $4.5 \%$ of all cancer cases which in 2008 reached 6046 (3). The aim of study was to assess the quality of life in patients' treatment due to head and/or neck cancer. Study was conducted of 48 patients $(52.08 \%$ men), treatment at the Oncology Center, Maria Skłodowska-Curie Institute in Warsaw, Poland, in 2015. The standardized questionnaire EORTC QLQ-C30 and QLQH\&N35 module for these patients.

The study was approved by the local Ethics Committee and the management of the hospital. All subjects gave their written informed consent to participation in the study.

The mean age was 56.29 $\pm 6.94 \mathrm{yr}$ (range: 43-67 yr). An equal number of respondents had location of tumour: larynx and laryngopharynx and oral cavity (43.75\% each) and oropharynx $(12.50 \%)$. Patients was treatment: radiotherapy $(54.17 \%)$; chemotherapy $(4.17 \%)$; surgical treatment $(2.08 \%)$; radiotherapy and chemotherapy
(33.33\%); surgery, radiotherapy and chemotherapy $(4.17 \%)$; surgery and radiotherapy (2.08\%). The mean value of subjective assessment of health condition reached $4.04 \pm 1.09$ and quality of life $3.79 \pm 1.17$. The statistical analysis did not reveal correlations between subjective assessment of health condition and level of quality of life and sex, age, location of tumour, stage, and type of treatment.

Each of aspects of physical function (difficulties in performing wearisome activities, fatigue during long and short walks, help required in the performance of everyday activities, limitations in the performance of everyday activities, limitations in pursuing hobbies, need for rest during the day and the sense of fatigue) was correlated with sex, age, location of tumour, stage and type of treatment. Physical function was affected solely by the stage and type of treatment. Thus, sex, age, location of tumour did not determine the physical ability of patients.

The sense of pain (dyspnoea, weakness and pain that made the performance of everyday activities 
more difficult) was not determined by variables: sex, age, location of tumour, stage and type of treatment.

$16.7 \%$ of patients ' health condition did not affect their family life, with $29.2 \%$ claimed there was no connection between their health condition and social life. Senior patients experienced significant or very significant difficulties $(P=0.01)$.

The results of QLQ-N\&H 35 questionnaire are illustrated in Table 1.

Table 1: The results of QLQ-H\&N35 questionnaire

\begin{tabular}{|c|c|c|c|c|}
\hline \multirow[t]{2}{*}{$Q L Q-H \& N 35$} & \multicolumn{4}{|c|}{$\mathbf{N}(\%)$} \\
\hline & None & Slight & Significant & Very significant \\
\hline Pain in the mouth & $10(20.8)$ & $19(39.6)$ & $11(22.9)$ & $8(16.7)$ \\
\hline Pain in the maxilla & $13(27.1)$ & $19(39.6)$ & $10(20.8)$ & $6(12.5)$ \\
\hline Oral sensitivity & $4(8.4)$ & $22(45.8)$ & $12(25.0)$ & $10(20.8)$ \\
\hline Sore throat & $4(8.4)$ & $18(37.5)$ & $16(33.3)$ & $10(20.8)$ \\
\hline Difficulties in swallowing of liquids & $7(14.6)$ & $17(35.4)$ & $18(37.5)$ & $6(12.5)$ \\
\hline Difficulties in swallowing of mashed foods & $8(16.7)$ & $20(41.7)$ & $11(22.9)$ & $9(18.7)$ \\
\hline Difficulties in swallowing of solid foods & $3(6.3)$ & $16(33.3)$ & $18(37.5)$ & $11(22.9)$ \\
\hline Choking when swallowing & $13(27.1)$ & $12(25.0)$ & $13(27.1)$ & $10(20.8)$ \\
\hline Teeth problems & $19(39.6)$ & $12(25.0)$ & $12(25.0)$ & $5(10.4)$ \\
\hline Difficulties in mouth opening & $10(20.8)$ & $18(37.5)$ & $17(35.4)$ & $3(6.3)$ \\
\hline Dry mouth & $1(2.1)$ & $19(39.6)$ & $22(45.8)$ & $6(12.5)$ \\
\hline Gluey saliva & $4(8.3)$ & $14(29.2)$ & $23(47.9)$ & $7(14.6)$ \\
\hline Impaired smell & 7 (14.6) & $22(45.8)$ & $12(25.0)$ & $7(14.6)$ \\
\hline Impaired taste & $2(4.2)$ & $15(31.3)$ & $18(37.5)$ & $13(27.1)$ \\
\hline Cough & $10(20.8)$ & $18(37.5)$ & $11(22.9)$ & $9(18.8)$ \\
\hline Hoarse voice & $10(20.8)$ & $17(35.4)$ & $12(25.0)$ & $9(18.8)$ \\
\hline Feeling sick & $6(12.5)$ & $17(35.4)$ & $17(35.4)$ & $8(16.7)$ \\
\hline Preoccupied with appearance & $11(22.9)$ & $13(27.1)$ & $13(27.1)$ & $11(22.9)$ \\
\hline Difficulties in eating & $7(14.6)$ & $17(35.4)$ & $13(27.1)$ & $11(22.9)$ \\
\hline Difficulties in eating with the family & $17(35.4)$ & $10(20.8)$ & $10(20.8)$ & $11(22.9)$ \\
\hline Difficulties in eating with other people & $17(35.4)$ & $12(25.0)$ & $13(27.1)$ & $6(12.5)$ \\
\hline Difficulties in deriving pleasure from eating & $6(12.5)$ & $19(39.6)$ & $14(29.2)$ & $9(18.8)$ \\
\hline Difficulties in speaking with other people & $12(25.0)$ & $17(35.4)$ & $11(22.9)$ & $8(16.7)$ \\
\hline Difficulties in phone conversations & $8(16.7)$ & $20(41.7)$ & $10(20.8)$ & $10(20.8)$ \\
\hline Difficulties in family communication & $19(39.6)$ & $12(25.0)$ & $12(25.0)$ & $5(10.4)$ \\
\hline Difficulties in social relations & $16(33.3)$ & $16(33.3)$ & $11(22.9)$ & $5(10.4)$ \\
\hline Difficulties when leaving someone else's house & $17(35.4)$ & $14(29.2)$ & $9(18.8)$ & $8(16.7)$ \\
\hline Difficulties in contacts with family and friends & $15(31.3)$ & $17(35.4)$ & $12(25.0)$ & $4(8.3)$ \\
\hline Decreased interest in sex & $16(33.3)$ & $16(33.3)$ & $13(27.1)$ & $6(12.5)$ \\
\hline Decreased satisfaction with sex & $15(31.3)$ & $14(29.2)$ & $12(27.1)$ & $6(12.5)$ \\
\hline
\end{tabular}

Oral sensitivity was more common among patients completed treatment compared against those who still received treatment $(P=0.04)$. Women reported primarily difficulties in swallowing of mashed foods $(P=0.03)$ and impaired smell $(P=0.02)$. A statistically significant relation was found between the sense of a dry mouth and the stage of treatment $(P=0.00)$. The difficulties associated with phone conversations were dependent on the health condition of patients
$(P=0.04)$. The difficulties in family communication significantly impaired the quality of life of patients $(P=0.01)$. No such relation was found in case of social relations. There was a correlation between satisfaction with sex and health condition of patients $(P=0.03)$.

\section{Acknowledgements}

The study was not sponsored (own resources). 


\section{Conflict of Interests}

The authors declare that there is no conflict of interest.

\section{References}

1. Mehanna H, Paleri V, West CM et al (2011). Head and neck cancer: Epidemiology, presentation, and preservation. Clin Otolaryngol, 36: 65-68.

2. Jemal A, Siegel R, Ward E et al (2007). Cancer statistics, 2007. CA Cancer J Clin, 57: 43-66.

3. Wojciechowska U, Didkowska J, Zatoński W (2008). Malignant neoplasms in Poland in 2008. Center of Oncology - Institute of Maria Sklodowska-Curie, Warsaw. Poland. 